\title{
Organização e representação do conhecimento arquivístico: em busca de um método para construção de tesauro funcional ${ }^{1}$
}

\author{
Maíra Fernandes Alencar \\ Mestra; Universidade Estadual de Londrina, Londrina, PR, Brasil; \\ alencarmfa@gmail.com \\ Brígida Maria Nogueira Cervantes \\ Doutora; Universidade Estadual de Londrina, Londrina, PR, Brasil; \\ brigidacervantes@gmail.com
}

\begin{abstract}
Resumo: A produção e o uso do conhecimento arquivístico no cenário das Tecnologias de Informação e Comunicação apresentam um ambiente complexo. Assim, refletir sobre as formas de representar o conhecimento arquivístico com instrumentos terminológicos contribui para o acesso informacional. Nessa perspectiva, os tesauros funcionais, como campo de estudo dentro da área, atuam como uma ferramenta complementar de solução aos problemas de acesso à informação arquivística. Em vista disso, este trabalho tem como objetivo realizar uma sistematização metodológica da construção de um tesauro funcional. Quanto aos procedimentos metodológicos, caracterizam-se como pesquisa bibliográfica e exploratória com abordagem qualitativa. Utiliza-se o método de análise de conteúdo de Bardin, que após a pré-análise e a exploração do material (literatura técnico-científica) agrupou-se as categorias: natureza pragmática conceitual, aspectos preliminares necessários e funções que o tesauro desempenha, além do aspecto teórico evidenciado, etapas e ações fundamentais para a construção do tesauro funcional. Verificou-se que, para a construção dos tesauros funcionais, o manual do Arquivo Nacional da Austrália, pioneiro em manual de tesauro funcional, descreve passos e ações necessárias para a sua construção. Conclui-se que essa trajetória da construção do tesauro funcional caminha por um estágio inicial, revelando a necessidade de aprofundamento teórico dessa temática junto a outras áreas do conhecimento.
\end{abstract}

Palavras-chave: Organização do conhecimento arquivístico. Tesauro funcional. Vocabulário controlado arquivístico.

\section{Introdução}

O conteúdo informacional dos documentos de arquivos revela a natureza do processo comunicativo humano, que está materializado em diferentes suportes e 
tipos documentais com as funções administrativas e jurídicas de atividades resultantes da missão de um arquivo organizacional ou pessoal.

O acesso informacional acontece quando há atividades de classificação e descrição que organizam e representam o conhecimento que está registrado (TOGNOLI, 2012), momento em que os elementos constituintes do processo comunicativo - o usuário interno, externo ou híbrido, com sua necessidade administrativa ou histórica - têm acesso e fazem uso da informação arquivística em fase corrente, intermediária ou permanente.

A padronização da linguagem dessas atividades, por meio do instrumento terminológico tesauro funcional, contribui para a recuperação da informação, uma vez que normaliza os termos (as funções) e cria acessos complementares. Nesse sentido, o tesauro funcional “[...] controla o vocabulário que designa a razão de ser do documento (sua função) e não o que ele contém (assunto).” (SMIT; KOBASHI, 2003, p. 44). Essa característica faz com que esse tipo de vocabulário controlado seja específico de documentos arquivísticos que já foram classificados. (NATIONAL ARCHIVES OF AUSTRALIA, 2003).

O campo de estudo do tesauro funcional está relacionado à área da Terminologia e da Linguística (AGUIAR; TALÁMO, 2012), visto que irá representar as funções por meio de termos, a partir da análise do contexto funcional, resultando em uma linguagem documentária.

$\mathrm{O}$ uso dos tesauros funcionais, enquanto acesso complementar às informações arquivísticas, está alinhado ao paradigma pós-custodial da área por ampliar o escopo do acesso informacional.

Justifica-se este trabalho devido à necessidade de pesquisas dessa abordagem, que contribui para que a temática de vocabulários controlados em arquivos possa ser ampliada teórica e metodologicamente, uma vez que na área ainda são escassas essas discussões (MOREIRA et al., 2015).

Dessa forma, para ampliar a busca de soluções para o problema de recuperação e acesso à informação arquivística, buscou-se, neste trabalho, realizar uma sistematização metodológica de como construir um tesauro funcional. 
A pesquisa é de natureza bibliográfica e exploratória com abordagem qualitativa. Utilizou-se o método de análise de conteúdo de Bardin, nesse sentido, para compor o corpus da pesquisa; delimitou-se a literatura técnicocientífica da área arquivística e sistematizou-se a análise nas seguintes categorias:

a) natureza pragmática conceitual;

b) aspectos preliminares necessários;

c) funções que o tesauro desempenha;

d) aspecto teórico evidenciado;

e) etapas de passos;

f) ações necessárias para a construção do tesauro funcional.

Verificou-se que o manual do Arquivo Nacional da Austrália2 descreve passos e ações necessárias para a construção de tesauros funcionais.

Conclui-se que essa trajetória de ampliação da relação dos estudos linguísticos com a área de Arquivística ainda está num caminho inicial, mas que o diálogo com a área da Organização e Representação do Conhecimento (ORC) encontra solo fértil para seu desenvolvimento. Tais resultados apontam, portanto, para uma necessidade de aproximação e aprofundamento teórico das áreas da Arquivologia, ORC, Ciência da Informação, Terminologia e Linguística para construir melhorias no processo metodológico da construção de tesauros funcionais que fornecem acesso às informações arquivísticas.

\section{Ciência da Informação, Organização do Conhecimento Arquivístico (OCA) e linguagem: As bases teóricas do tesauro funcional}

O que a Ciência da Informação (CI) se propõe a organizar e representar? A informação e o conhecimento. O termo "informação" existe em diferentes áreas do saber humano e pode ter diversos significados em cada uma delas. Mas, e para a CI, o que é informação? Que tipo de informação essa área irá tratar? Capurro e Hjørland abordam sobre esse aspecto: 
Existem muitos conceitos de informação e eles estão inseridos em estruturas teóricas mais ou menos explícitas. Quando se estuda informação, é fácil perder a orientação. Portanto, é importante fazer a pergunta pragmática: 'Que diferença faz se usarmos uma ou outra teoria ou conceito de informação?' Essa tarefa é difícil porque muitas abordagens envolvem conceitos implícitos ou vagos que devem ser esclarecidos. (CAPURRO; HJØRLAND, 2007, p. 193, grifo do autor).

Os autores supracitados argumentam que esses esclarecimentos tendem a causar resistência, já que o termo "informação" tem sido usado com recursos de status ao invés de recursos teóricos. Através dessa abordagem, os teóricos argumentam sobre a ampliação do conceito de informação no intuito de trazer contribuições ao campo da CI.

Com esse estudo, pode-se ressaltar uma distinção essencial que Capurro e Hjørland (2007, p. 193) descrevem da informação como coisa/objeto (visão de Buckland) ou como signo (que precisa ser interpretado por um agente cognitivo). Ao inserir esses aspectos, o que fica evidente é que informação, na visão interpretativa da CI, tende a ser mais pragmática - essa possibilidade de compreensão da informação terá seu significado centrado nos contextos social e cultural, características essas que são vertentes do atual paradigma que estamos emergidos.

O que caracteriza uma área dentro da modernidade é o paradigma que a rege. Tal conceito pode ser entendido, segundo Lopes Yepes (2016), como um conjunto de características que merecem ser campos de estudo e discussão dentro de uma área do conhecimento.

A ciência, enquanto construção histórica de um tempo, fruto das ações humanas em constantes mudanças, traz consigo novas concepções de pensamento e fazeres a cada novo modelo de transformações. Isso influencia, em âmbito social, todos os campos do conhecimento. Logo, a área da CI também teria reflexos dessas características. O que notamos com isso é uma área que, ao longo do seu desenvolvimento, caminha por diferentes paradigmas. Nesse sentido, os conceitos de informação estão ligados aos diferentes paradigmas epistemológicos da área da CI: físico, cognitivo e social. 
O conjunto de características do paradigma físico centra-se na Teoria Matemática da Comunicação (TMC) de Shannon e Weaver $\left(1942^{3}\right.$ apud Capurro, 2003), a qual postula que há um objeto físico transmitido a um receptor através de um emissor; nessa vertente, não há a denominação de transmissão de informação, mas sim de mensagem, além de haver a exclusão do usuário do processo informacional.

Considerando esses aspectos, é proposto por Brookes, em 1977/1980 (apud Capurro, 2003), um novo conjunto de características para nortear a área, intitulado de paradigma cognitivo. Percebendo a necessidade do usuário no processo informacional, ele é colocado como vertente vital; assim, verifica-se de que forma os processos da informação transformam ou não o usuário. Porém, esse modelo não aborda o meio social em que está situado o usuário, o que também terá impacto no processo de transformação desse, por meio de um registro informacional.

O autor Frohman (1995, apud Capurro, 2003), fundamentado em Wittgenstein (1958 apud Capurro, 2003) e Foucault (1994, apud Capurro, 2003), critica essa última vertente, pois argumenta que essa forma de reger a área é reducionista e associal, uma vez que ignora a construção social dos processos informacionais. Também defendem esse viés social Hjørland e Albrechtsen (1995, apud Capurro, 2003), ao delimitarem que um campo cognitivo de estudo tem relação com os grupos sociais, chamando esses de comunidades discursivas.

Assim, o que vem posteriomente a prevalecer é o paradigma social, cuja busca ideal não se pauta na representação da informação, mas sim na análise de acordo com o contexto social de relevância e critério do grupo em questão (CAPURRO, 2003).

Silva e Ribeiro (2002) argumentam que, verificados todos os processos históricos da área, o conceito que a configurou não está em harmonia, uma vez que seu nível ontológico tem maior abrangência do que seu suporte material. Dessa forma, questiona-se: como é possível reduzir a informação à documentação? 
Os autores ampliaram o olhar para considerar não apenas a visão custodiadora e tecnicista do documento, mas também o processo informacional que é resultado materializado dos fenômenos humanos e sociais.

Nota-se que essa ampliação está contida no conceito de informação:

[...] um conjunto estruturado de representações mentais codificadas (símbolos significantes) socialmente contextualizadas e passíveis de serem registradas num suporte material qualquer (papel, filme, banda magnética, disco compacto, etc.) e, portanto, comunicadas de forma assíncrona e multidirecionadas. (SILVA; RIBEIRO, 2002, p. $37)$.

A continuidade desse pensamento ocorre quando os autores supracitados (SILVA; RIBEIRO, 2002) constatam que o registro material ou físico torna possível a existência da informação, mas não a faz ser. Ou seja, sua essência é de natureza social e psíquica - reside na mente humana e, também na interação social com o ambiente em que vivem os sujeitos. De acordo com os autores, essa interação é representada por um código: a língua. Essa característica é de natureza humana e é diferente da ação de materializá-la em um suporte físico externo.

Um exemplo disso pode ser: um grupo de amigos conversam entre si e, nesse diálogo, utilizam informações para comunicar-se. Tal comunicação é realizada pela fala; esse código, a língua, faz parte deles, por isso não necessita de nenhum meio externo para acontecer. Quando ocorre alguma intenção de ação para a posterioridade, ela é externalizada em algum suporte físico, por exemplo, uma fotografia ou um registro textual do momento.

A partir desse ponto, Silva e Ribeiro (2002, p. 42) sistematizam seis propriedades intrínsecas da informação:

1) estruturação pela ação (humana e social) - o ato individual e/ou coletivo funda e modela estruturalmente a informação;

2) integração dinâmica - o ato informacional está implicado ou resulta sempre tanto das condições e circunstâncias internas, como das externas do sujeito da ação;

3) pregnância - enunciação (máxima ou mínima) do sentido ativo, ou seja, da ação fundadora e modeladora da informação;

4) quantificação - a codificação linguística, numérica ou gráfica é valorável ou mensurável quantitativamente;

5) reprodutividade - a informação é reprodutível sem limites, possibilitando a subsequente retenção/memorização; 
6) transmissibilidade - a (re)produção informacional é potencialmente transmissível ou comunicável (SILVA; RIBEIRO, 2002, p. 43, grifos nossos).

Uma outra contribuição está em Rendón Rojas (2005), o qual argumenta que a informação tem sua fonte no mundo material; o conhecimento, por sua vez, provém do sujeito. Para essa argumentação, o referido autor fundamenta-se na teoria psicogenética de Piaget, em que o conhecimento é algo construído pelo indivíduo com base na assimilação, integração e reorganização das estruturas que permitem interpretar o mundo e interagir com ele.

Para o autor supracitado (RENDÓN ROJAS, 2005), o mundo faz-se ausente de sentido: quem o confere tal sentido e significações são os seres humanos. Nesse processo, é necessário identificar a existência de valor, que traz consigo o questionamento sobre se o objeto desejado (as ações humanas) permite o desenvolvimento do ser humano - não individual, mas comunitário. Essa abordagem evidencia uma relação com o paradigma social da CI.

Dentro desse viés epistemológico social, os efeitos da ação de informar mostram que conforme o ser humano recebe informação, ele também informa. Esse processo é cíclico e determinante em relação ao que será a informação para a área, assim menciona Araújo (2014):

[...] os seres humanos em suas diferentes ações no mundo (produzir pesquisa científica, construir sua identidade, monitorar o ambiente mercadológico, testemunhar direitos e deveres, etc.), produzem registros materiais, documentos - eles in-formam. É essa ação de produzir registros materiais que é a informação, que é o objeto de estudo da Ciência da Informação. A Ciência da Informação não estuda a ação administrativa, política ou cultural em si mesmas, mas apenas naquilo que elas têm de informacional.[...] Ao mesmo tempo, ainda, os seres humanos, também em suas diferentes ações (tomar decisões de investimentos, testemunhar determinados direitos, comunicar-se com os outros, etc.), utilizam esses documentos, esses registros materiais - os seres humanos se informam. É também essa ação de utilizar, se apropriar dos registros de conhecimento que é a informação, e que é também objeto de estudo da CI. (ARAÚJO, 2014, p. 24-25, grifo nosso).

Para que seja possível, portanto, fazer uso da informação, o campo da Organização do Conhecimento (OC) oferece vertentes teóricas e práticas. 
A CI, enquanto área participativa do fluxo da informação e conhecimento, realiza esforços para que os conceitos de seus campos possam estar alinhados e existir. Dessa forma, verifica-se que, no que tange à $\mathrm{OC}$, recuperamos aqui duas visões: na primeira, os autores entendem que a disciplina da OC é dedicada ao estudo e desenvolvimento dos:

[...] fundamentos e técnicas da planificação, construção, gestão, uso e evolução dos sistemas de descrição, catalogação, ordenação, classificação, armazenamento, comunicação e recuperação dos documentos criados pelo homem para testemunhar, conservar e transmitir seus saberes e seus atos, a partir de seu conteúdo, com o objetivo de garantir sua conversão em informação capaz de gerar novos conhecimentos. (ESTEBAN NAVARRO; GARCÍA MARCO, 1995, p. 149, tradução nossa, grifo noso).

Já na segunda conceituação, Hjørland (2008) argumenta em dois níveis seu conceito: no sentido específico, a OC trata "[...] sobre atividades como descrição do documento, indexação e classificação realizada em bibliotecas, bases de dados bibliográficos, arquivos e outros tipos de instituições de memória [...]" (HJØRLAND, 2008, p. 86, tradução nossa); e, no sentido amplo, o teórico argumenta tratar-se de uma

[...] divisão social do trabalho mental, ou seja, a organização de universidades e outras instituições para pesquisa e educação, estrutura de disciplinas e profissões, a organização social dos meios de comunicação, etc [...] (HJØRLAND, 2008, p. 86, tradução nossa).

Ao analisar esses conceitos sob o ângulo da Arquivística, verifica-se que a organização e a representação do conhecimento na área encontram-se no âmbito específico, que ocorre por meio de dois processos nucleares: a classificação e a descrição (TOGNOLI; BARROS, 2015). Ilustra-se tal perspectiva na figura 1 : 
Figura 1 - Processos Nucleares da OCA

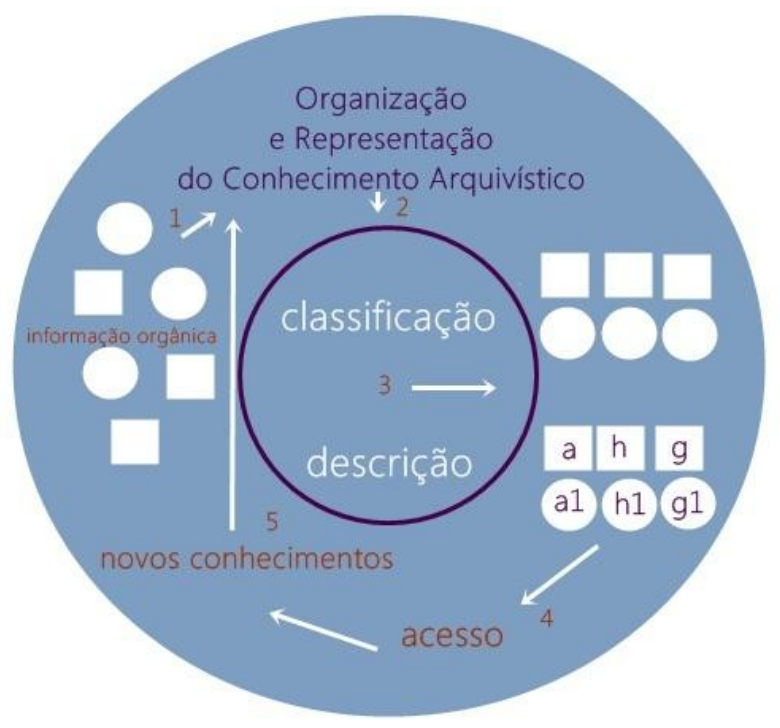

Fonte: Elaborado pelas autoras com base em Tognoli e Barros (2015).

$\mathrm{Na}$ abordagem de Hjørland, o específico só existe em detrimento do amplo. Por conseguinte, não existiria o sentido específico se não houvesse o amplo, dessa forma o autor insere que:

[...] a importância de considerar o campo amplo da OC relaciona-se à questão sobre como a OC no sentido específico pode ser desenvolvida. [...] O sentido específico não pode desenvolver um corpo frutífero de conhecimento sem considerar a OC numa perspectiva ampla. Em outras palavras: não existe um 'universo do conhecimento' fechado que pode ser estudado pela OC isoladamente de todo o estudo das outras ciências da realidade. (HJØRLAND, 2008, p. 87, tradução nossa).

Esse desenvolvimento sobre o qual o autor argumenta pode ser compreendido enquanto uma base que permeia as ações metodológicas ou teóricas que irão incidir nas práticas dos campos da CI: arquivos, museus, bibliotecas e centros de memória e documentação. Assim, nota-se que é preciso considerar, portanto, o sentido amplo, para que as áreas da CI possam ter progressos e confluências na perspectiva da OC.

Mas quais são as áreas do sentido amplo que podem contribuir com o sentido específico? Ou, em outras palavras, ao abordar este trabalho na ótica da 
Arquivística, que tem seus processos nucleares condizentes com as teorias da OC, o que concordante ao campo amplo, poderia contribuir para o objeto do trabalho aqui exposto (no caso, a organização e representação das linguagens orgânicas-funcionais por meio da padronização terminológica)?

Hjørland (2008) menciona algumas disciplinas como principais no sentido amplo, dentre as quais está a Linguística. Dessa forma, para responder ao enunciado acima, vale utilizá-la, uma vez que os documentos, na Arquivística, só existem porque há a linguagem na sociedade; caso contrário, não haveria a linguagem materializada nos documentos de arquivo. Ao recuperar essa abordagem entre quanto do amplo está inserido no específico, torna-se possível agrupar aspectos que contribuam para a área da Arquivística. E, nesse sentido, a linguagem é um deles.

Ao analisar essa importância da linguagem na Arquivística, nota-se que ela está contida nas funções nucleares da organização do conhecimento arquivístico (OCA) - a classificação e a descrição. Verifica-se que todo esse processo alimenta o sentido do conhecimento arquivístico, uma vez que a linguagem, enquanto disciplina, irá organizar a realidade humana, sendo posteriormente materializada em documentos que nascem em decorrência de funções específicas nas organizações. Esses registros são classificados e descritos para viabilizar seu acesso à informação orgânica, e, através desse acesso, o ciclo torna-se contínuo. Essa abordagem encontra-se ilustrada na figura 2: 
Maíra Fernandes Alencar e Brígida Maria Nogueira Cervantes

Figura 2 - Sentido amplo e específico da OC: da Linguística às atividades da OCA para o

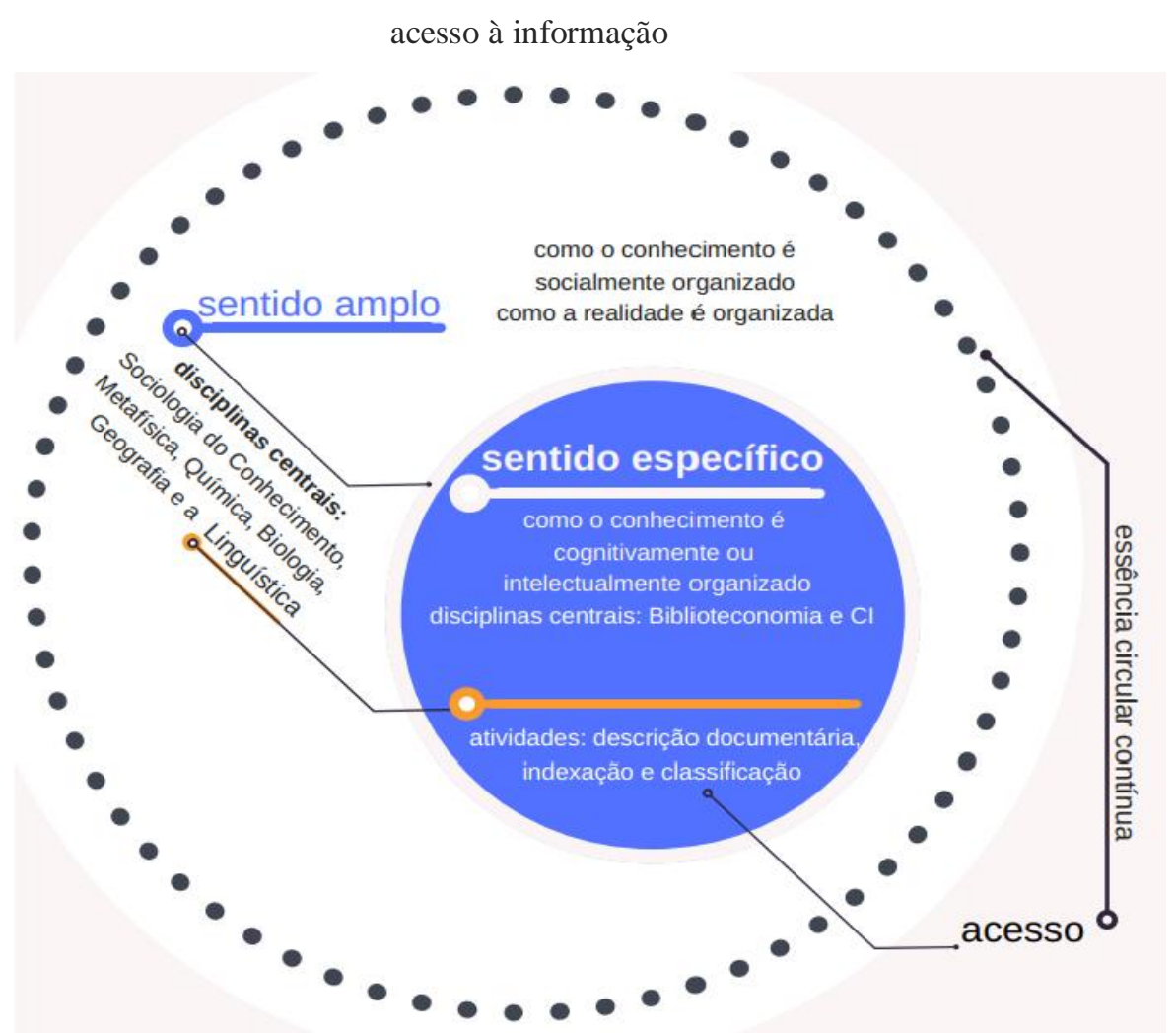

Fonte: Elaborado pelas autoras com base em Hjørland (2008).

Para Hjørland (2008), a Linguística (que é a área de estudo da linguagem) é uma das disciplinas que fazem parte da organização da realidade/conhecimento social. Nesse sentido, o mesmo aspecto é materializado nos documentos arquivísitos; porém, verifica-se que, depois que a informação orgânica registrada passa pelos processos da OCA, obtém-se uma nova representação da linguagem, condizente com a função que originou $o$ documento: o plano de classificação e os guias/catálogos/inventários.

Ressalta-se aqui que um dos elementos o qual poderá complementar essa representação com uma padronização atuará enquanto um ponto de acesso complementar. Antes de aprofundar tal aspecto, recuperam-se, a seguir, as ligações conceituais entre os fatores linguagem e conhecimento, que são insumos para possibilitar o acesso à informação na Arquivística, pois, de acordo com Bufrem, Arboit e Sorribas (2012), “[...] não se pode ter acesso à informação e, logo, ao conhecimento, sem o intermédio da linguagem.” (BUFREM; ARBOIT; SORRIBAS, 2012, p. 267). 
Para Fogl (19794, p. 21 apud BRASCHER; CAFÉ, 2008, p. 3), a informação "[...] compreende uma unidade de três elementos: 1. Conhecimento (conteúdo da informação); 2. Linguagem (um instrumento de expressão de itens de informação); 3. Suporte (objetos materiais ou energia)." (FOGL, 19795 , p. 21 apud BRASCHER; CAFÉ, 2008, p. 3).

Em razão de a língua ter sua natureza ligada ao contexto histórico-social, Cintra e outras (2002) conceituam-na enquanto um "[...] sistema-estrutura de valores e formas." (CINTRA et al., 2002, p. 20). Esses “[...] não são construções particulares de um indivíduo; são antes o resultado de todo um contexto sócio-histórico que determina as condições de produção do discurso." (CINTRA et al., 2002, p. 22). Para exemplificar, a informação registrada notadamente é um produto do discurso humano.

Mais amplamente, é também um sistema de símbolos ${ }^{6}$ já que os “[...] sistemas de símbolos, orais ou escritos, mais importante na troca de informação é, sem dúvida, a língua. Os recursos linguísticos são usados para identificar, ordenar e relacionar os signos e os símbolos contidos nos registros [...]" (SILVA et al., 1999, p. 26).

O que se infere a partir de tais enunciados é: como a linguagem é origem e causa das relações humanas em suas atividades - refletindo sobre a questão do acesso ao conhecimento produzido em contextos específicos (do campo da Arquivística) por meio da informação registrada -, determina-se que, nesses ambientes informacionais, o acesso ocorre mediante uma linguagem própria para aquele fim. Ou seja, uma linguagem para comunicar o documento; por isso, denomina-se linguagem documentária.

Nesse sentido, se o objetivo é comunicar o documento e esse varia entre diferentes contextos, nota-se que as Linguagens Documentárias (LDs) reapresentam o conteúdo informacional por meio de uma nova construção. Dessa forma, aquilo que se pretende comunicar será dito de outra forma, agora padronizada e sintetizada, pois passou por um tratamento, uma análise com objetivo de dar condições ao acesso.

Ressalta-se, porém, que as LDs só existem devido a uma grande 
quantidade de documentos. Isso justifica a ocorrência de seus estudos na CI na década em que houve difusão dos saberes científicos e tecnológicos. Visto que as LDs são, portanto, uma nova apresentação dos conteúdos documentais, é de sua natureza comportar diferentes elementos dos seguintes campos da Linguística: léxico, vocabulário, nomenclatura e terminologia (CINTRA et al., 2002). Para construir uma LD, parte-se do princípio de que deve haver uma necessidade específica, pois o contexto é que norteará todo processo de análise documental para as atividades com o processo de representação da Linguagem Natural (LN) para a LD.

Esse foco para um contexto específico, dentro das questões de representação da informação, é uma característica da visão pragmática, que Hjørland (2008) cita nos estudos sobre o uso dos conceitos. Tal visão aplica-se no campo das LDs na medida em que representar assuntos envolve mutuamente a organização de conceitos. Assim, para cada tipo de conhecimento específico, um tipo de LD é inserido.

Dentre os tipos de LDs estão os sistemas de classificação e o tesauro "As diferenças entre esses dois tipos de LDs reside no maior ou menor grau de reprodução das relações presentes na $\mathrm{LN}$ e no universo de conhecimento que pretendem cobrir." (CINTRA et al., 2002, p. 29). As autoras complementam dizendo que a ação de representar determinados universos do conhecimento para os usuários não dá às LDs condição de substituir o conteúdo documental, mas sim de atuar enquanto uma ferramenta representativa/indicativa.

Nesse sentido, entende-se que uma sugestão para a padronização terminológica na Arquivística são os tesauros funcionais, para atuarem enquanto ponto complementar de acesso - aspecto esse que precisa encontrar bases metodológicas para a sua construção.

\section{Procedimentos metodológicos}

A pesquisa caracteriza-se como bibliográfica e exploratória com abordagem qualitativa. 
O método utilizado é a análise de conteúdo, que, de acordo com Bardin (2003), teve seu desenvolvimento primeiramente nos Estados Unidos - com âmbito inicial no campo jornalístico - e só obteve maior impacto depois da Segunda Guerra Mundial, quando se inicia a ênfase sobre a investigação política através da análise de mensagens da comunicação dentro da imprensa, com foco nas propagandas políticas. O método de análise de conteúdo é compreendido enquanto:

[...] um conjunto de técnicas de análise das comunicações. Não se trata de um instrumento, mas de um leque de apetrechos; ou, com maior rigor, será um único instrumento, mas marcado por uma grande disparidade de formas e adaptável a um campo de aplicação muito vasto: as comunicações. (BARDIN, 2003, p. 31)

As etapas do método foram empregadas da seguinte forma:

a) pré-análise - composição do corpus, literatura técnico-científica - busca por manuais de instruções da construção de tesauro funcional da área arquivística da Austrália (país pioneiro em tesauro funcional) e do Brasil (país em que a pesquisa é realizada) que descrevessem o processo de construção de um tesauro funcional, considerando como critério estar disponível na Web, em arquivos públicos nacionais ou estaduais, conforme tabela abaixo;

Quadro 1 - Metodologia para sistematização teórica para compor o corpus da pesquisa literatura técnico-científica

\begin{tabular}{|c|c|c|c|c|}
\hline $\begin{array}{l}\text { TEMA EM } \\
\text { BUSCA DE } \\
\text { MÉTODO }\end{array}$ & $\begin{array}{c}\text { ORIGEM } \\
\text { HISTÓRICA }\end{array}$ & $\begin{array}{l}\text { ORIGEM DE } \\
\text { APLICAÇÃO }\end{array}$ & FORMATO & CRITÉRIO \\
\hline $\begin{array}{l}\text { - Tesauro } \\
\text { Funcional }\end{array}$ & - Austrália & - Brasil & $\begin{array}{l}\text { - Manuais de } \\
\text { como fazer. }\end{array}$ & $\begin{array}{l}\text { - Disponíveis } \\
\text { na internet, } \\
\text { oriundos de } \\
\text { Arquivos } \\
\text { Públicos } \\
\text { Nacionais ou } \\
\text { Estaduais. }\end{array}$ \\
\hline
\end{tabular}

Fonte: Elaborado pelas autoras.

b)exploração do material - leituras e análises dos materiais recuperados; 
c) tratamento dos resultados, a inferência e a interpretação - criação de categorias em (1) natureza pragmática conceitual; (2) aspectos preliminares necessários; (3) funções que o tesauro desempenha; (4) aspecto teórico evidenciado e (5) etapas e ações fundamentais para a construção do tesauro funcional.

A Arquivística, enquanto uma área de aplicação dentro das organizações é fruto de uma sistematização teórica e de uma prática milenar. Em decorrência dessa característica, é notável o desenvolvimento de sua literatura técnicocientífica buscando oferecer parâmetros de como realizar as atividades da gestão documental, aspecto que contribui para a escolha metodológica de buscar, nessa literatura, as bases de como construir tesauros funcionais.

\section{Análise dos resultados}

Recuperou-se, um total de dois manuais para compor o corpus da literatura técnico-científica.

Após a leitura dos materiais, sistematizaram-se as seguintes categorias: (1) natureza pragmática conceitual (representada pelo conceito e dimensões que ele abrange); (2) aspectos preliminares necessários; (3) funções que o tesauro funcional desempenha; (4) aspecto teórico evidenciado e (5) etapas de passos e ações necessárias para sua construção.

Quadro 2 - Resultados da Sistematização Metodológica: como construir tesauro funcional

\begin{tabular}{|l|l|l|}
\hline Variáveis & $\begin{array}{l}\text { Arquivo Nacional da Austrália } \\
\text { 2. Construindo um tesauro } \\
\text { funcional }\end{array}$ & $\begin{array}{c}\text { Smit e Kobashi } \\
\text { 3.3. A construção de um } \\
\text { tesauro funcional }\end{array}$ \\
\hline \multirow{2}{*}{$\begin{array}{l}\text { Natureza } \\
\text { pragmática } \\
\text { conceitual }\end{array}$} & $\begin{array}{l}\text { Um tesauro funcional é uma } \\
\text { ferramenta de classificação para }\end{array}$ & $\begin{array}{l}\text { Um tesauro funcional } \\
\text { ajudar as organizações a gerenciar } \\
\text { seus registros e outrola o vocabulário } \\
\text { que designa a razão de ser }\end{array}$ \\
& $\begin{array}{l}\text { informações comerciais. É uma } \\
\text { lista controlada de termos unidos documento (sua } \\
\text { por relações semânticas, } \\
\text { hierárquicas, associativas ou de }\end{array}$ & $\begin{array}{l}\text { funçáo) e não o que ele } \\
\text { p. 44) (assunto). (2003, }\end{array}$ \\
\hline
\end{tabular}




\begin{tabular}{|c|c|c|}
\hline & $\begin{array}{l}\text { equivalência. Essa ferramenta } \\
\text { atua como um guia para atribuir } \\
\text { os termos de classificação aos } \\
\text { registros individuais. (p. } 7 \text { ) } \\
\text { Um tesauro funcional pode } \\
\text { abranger apenas as funções } \\
\text { principais que a organização } \\
\text { executa ou pode descrever a } \\
\text { totalidade das funções } \\
\text { desempenhadas pela organização. } \\
\text { As funções principais são } \\
\text { responsabilidades únicas da } \\
\text { organização. (2003, p. 16) }\end{array}$ & \\
\hline $\begin{array}{l}\text { Aspectos } \\
\text { preliminares } \\
\text { necessários }\end{array}$ & $\begin{array}{l}\text { Parte do esquema de } \\
\text { classificação. }(2003, \text { p. } 6)\end{array}$ & $\begin{array}{l}\text { A sua construção partirá } \\
\text { do plano de classificação } \\
\text { e o reordenará. (Nunca é } \\
\text { demais salientar que um } \\
\text { tesauro funcional não } \\
\text { substitui tal plano.). } \\
(2003, \text { p. } 44)\end{array}$ \\
\hline $\begin{array}{l}\text { Funções que ele } \\
\text { desempenha }\end{array}$ & $\begin{array}{l}\text { O principal objetivo de um } \\
\text { tesauro funcional é permitir aos } \\
\text { usuários navegar entre os termos } \\
\text { que podem ser usados para } \\
\text { classificar, descrever e recuperar } \\
\text { registros e outras informações da } \\
\text { instituição. } \\
\text { Construir um tesauro de funções } \\
\text { envolve a criação de relações } \\
\text { lógicas entre funções de negócios, } \\
\text { atividades e tópicos. } \\
\text { Na linguagem do tesauro há } \\
\text { relacionamentos dos termos de } \\
\text { relações gerais, específicas, } \\
\text { relacionadas e de equivalência, e } \\
\text { também de termos não preferidos. } \\
\text { (2003, p. 16) }\end{array}$ & $\begin{array}{l}\text { - opera como índice de } \\
\text { termos do plano de } \\
\text { classificação; } \\
\text { - opera como índice para } \\
\text { encontrar séries } \\
\text { documentais a serem } \\
\text { eliminadas; } \\
\text { - provê pontos de acesso } \\
\text { ao usuário, permitindo } \\
\text { navegar de sinônimos, ou } \\
\text { outros termos não } \\
\text { adotados, para a } \\
\text { terminologia adotada pelo } \\
\text { arquivo; } \\
\text { - pode ser usado como } \\
\text { ferramenta para ajudar o } \\
\text { funcionário a encontrar } \\
\text { documentos necessários } \\
\text { para as tarefas do dia a } \\
\text { dia. } \\
\text { (2003, p. } 45 \text { ) }\end{array}$ \\
\hline $\begin{array}{l}\text { Aspecto teórico } \\
\text { evidenciado }\end{array}$ & $\begin{array}{lcr}\begin{array}{l}\text { Perspectiva } \\
\text { informação } \\
\text { processos. }\end{array} & \text { gerada acesso à } \\
\end{array}$ & $\begin{array}{l}\text { Perspectiva de acesso à } \\
\text { informação gerada pelos } \\
\text { processos. }\end{array}$ \\
\hline $\begin{array}{l}\text { Etapas de passos e } \\
\text { ações necessárias } \\
\text { para sua } \\
\text { construção }\end{array}$ & $\begin{array}{l}\text { Consta das funções principais } \\
\text { (quadro 1) e das funções } \\
\text { complementares. }\end{array}$ & Não consta. \\
\hline
\end{tabular}

Fonte: Elaborada pelas autoras com base em National Archives of Australia (2003), Smit e 
Delimitou-se, para esta pesquisa, um passo a passo das etapas da elaboração de um tesauro das funções principais. No Quadro 3, apresenta-se uma sistematização conforme o manual do Arquivo Nacional da Austrália:

Quadro 3 - Passo a passo do processo de construção de um tesauro de funções principais

\begin{tabular}{|c|c|}
\hline Passos & Ações \\
\hline 1 & $\begin{array}{l}\text { - Digite os termos da função principal do esquema de classificação comercial. } \\
\text { Certifique-se de que esses são marcados como termos preferidos. } \\
\text { - Digite quaisquer termos de função adicionais concebidos para acomodar os } \\
\text { requisitos do usuário. Marque-os como termos preferidos. } \\
\text { - Insira notas de escopo ao lado do termo de função. } \\
\text { - Reconheça a fonte do termo, que será sua organização específica, pelo } \\
\text { esquema de classificação. } \\
\text { - Assegure que os termos sejam classificados em ordem alfabética. }\end{array}$ \\
\hline 2 & $\begin{array}{l}\text { - Digite os principais termos de atividade do esquema de classificação } \\
\text { empresarial da organização e assegure-se de que esses são marcados como } \\
\text { termos preferenciais. } \\
\text { - Digite os termos adicionais do nível de atividade desenvolvidos para } \\
\text { acomodar os requisitos dos usuários (por exemplo, "maços" e "tipos de } \\
\text { atividades" de "atividades mega") e assegure-se de que sejam marcados como } \\
\text { termos preferenciais. } \\
\text { - Insira notas de escopo próximas ao termo de atividade. } \\
\text { - Reconheça a fonte do termo, por exemplo: palavra-chave AAA ou o } \\
\text { esquema de classificação de negócios específico da sua organização. } \\
\text { - Assegure que os termos estejam classificados em ordem alfabética. }\end{array}$ \\
\hline 3 & $\begin{array}{l}\text { - Insira os termos formulados para o terceiro nível de classificação. Esses } \\
\text { termos de tópicos podem estar relacionados a grupos de transações, que } \\
\text { podem incluir conceitos de assunto, tipos de Oregistro ou abreviaturas usados } \\
\text { na organização. Idealmente, esses termos não devem ter mais de duas } \\
\text { palavras. } \\
\text { - Certifique-se de que estes termos sejam marcados como termos preferidos. } \\
\text { - Se uma nota de escopo for necessária para explicar o termo, insira-a } \\
\text { adjacente ao termo. } \\
\text { - Reconheça a origem do termo. } \\
\text { - Assegure que os termos estejam classificados em ordem alfabética. }\end{array}$ \\
\hline 4 & $\begin{array}{l}\text { - Estabeleça relacionamentos mais amplos e mais estreitos. Esses } \\
\text { relacionamentos ocorrerão simultaneamente na maioria dos aplicativos de } \\
\text { sinônimos. } \\
\text { - Certifique-se de que os termos da função tenham uma relação BT (Termo } \\
\text { Geral) com cada termo de atividade realizado para executar a função. } \\
\text { - Certifique-se de que os termos de atividade tenham uma relação NT (Termo } \\
\text { Específico) com os termos de função aos quais eles estão conectados. } \\
\text { - Assegure-se de que os termos de atividade tenham uma relação BT para } \\
\text { cada tópico. } \\
\text { - Execute a atividade. } \\
\text { - Assegure-se de que os termos do tópico tenham uma relação NT para cada } \\
\text { termo de atividade a que se relacionam. }\end{array}$ \\
\hline 5 & $\begin{array}{l}\text { - Estabeleça relações associativas com uma etiqueta RT (Termo Relacionado) } \\
\text { para termos no mesmo nível. Por exemplo, um termo de função só pode ter } \\
\text { uma relação RT com outro termo de função, e um termo de atividade só pode }\end{array}$ \\
\hline
\end{tabular}




\begin{tabular}{|c|c|}
\hline & $\begin{array}{l}\text { • Essas relações RT ocorrerão simultaneamente na maioria dos aplicativos de } \\
\text { sinônimos. }\end{array}$ \\
\hline 6 & $\begin{array}{l}\text { - Digite os termos não preferidos. Esses são variações nos termos } \\
\text { preferenciais, terminologia desatualizada, variações ortográficas, etc., usadas } \\
\text { na organização para descrever funções, atividades e tópicos. Esses termos são } \\
\text { colocados no dicionário de sinônimos, mas não são considerados aceitáveis } \\
\text { para uso. } \\
\text { - Indique a relação de equivalência, ligando o termo não preferido ao termo } \\
\text { preferido. Certifique-se de que o termo preferido tenha uma etiqueta } \\
\text { "USAR". } \\
\text { - Assegure que os termos estejam classificados em ordem alfabética. }\end{array}$ \\
\hline 7 & $\begin{array}{l}\text { que-se de que os termos não preferidos sejam inseridos no termo } \\
\text {. } \\
\text { e relação de equivalência, anexando uma marca "USAR PARA" ao } \\
\text { lo preferido. }\end{array}$ \\
\hline 8 & $\begin{array}{l}\text { - Revise a listagem e assegure-se de que nenhum relacionamento ilógico } \\
\text { tenha sido criado. }\end{array}$ \\
\hline \multicolumn{2}{|r|}{$\begin{array}{l}\text { A construção do dicionário de sinônimos não precisa ser conduzida em estrita } \\
\text { conformidade com o processo descrito acima. Pode-se começar no nível do tópico. O } \\
\text { ponto importante a lembrar é que as relações devem ser estabelecidas de acordo com as } \\
\text { egras do dicionário de sinônimos. }\end{array}$} \\
\hline
\end{tabular}
Fonte: National Archives of Australia (2003, p. 18-19, tradução nossa).

Sobre a análise realizada por meio dos manuais, nota-se que Smit e Kobashi (2003) ampliaram o olhar sobre a importância de trazer à tona a questão da padronização por meio dos tesauros para a Arquivística. Além disso, através dos estudos acerca do tesauro funcional, contribuíram de forma sintética e objetiva, abrindo caminhos para pesquisas nesse cenário. Por conta do sintetismo, não há no manual a descrição das etapas de construção do tesauro. Porém, nesse aspecto, o Arquivo Nacional da Austrália contribui numa abordagem metodológica. A explicação dos passos e das ações a serem seguidos para sua construção permite o desenvolvimento de uma operacionalização dos vocabulários na linguagem funcional.

\section{Considerações Finais}

A linguagem é a ponte entre a informação arquivística e o acesso. Questionar-se sobre como atravessar e percorrer essa ponte não só justifica a existência das 
instituições arquivísticas, como também influencia a atuação da Arquivística no plano social, cultural e científico.

Dentro desse panorama, os tesauros funcionais revelam-se condizentes com esse objetivo de fornecer acessos, ou seja, caminhos aos conhecimentos produzidos e recebidos dentro de um contexto organizacional.

Este estudo buscou, na literatura técnico-científica, manuais que descrevessem como esses tesauros podem ser construídos. Recuperaram-se dois manuais, um de contexto brasileiro e outro de contexto australiano - sendo esse último o pioneiro nessa temática e o que possui maior profundidade em seu passo a passo para nortear a construção.

Pode-se inferir que é possível aprimorar e ampliar os estudos voltados para a construção e aplicação dos tesauros funcionais. Nesse sentido, aproximações teóricas e metodológicas entre as áreas da Arquivologia, ORC, Ciência da Informação, Terminologia e Linguística são necessárias.

\section{Financiamento}

CAPES (Coordenação de Aperfeiçoamento de Pessoal de Nível Superior).

\section{Agradecimentos}

Agradecemos às professoras Dra. Ana Cristina de Albuquerque e Dra. Natália Bolfarini Tognoli pelas sugestões necessárias e essenciais durante a qualificação e defesa da dissertação da qual este trabalho foi extraído.

\section{Referências}

AGUIAR, F. L.; TALÁMO, M. F. G. M. O Controle de vocabulário da linguagem orgânico-funcional: concepção e princípios teórico-metodológicos. Acervo, Rio de Janeiro, v. 25, n. 1, p. 117-138, jan./jun. 2012.

ALENCAR, Maíra Fernandes. Organização e representação do conhecimento na arquivística: abordagens para construção de tesauros funcionais. 2017. Dissertação (Mestrado em Ciência da Informação) - Programa de PósGraduação em Ciência da Informação, Universidade Estadual de Londrina, Londrina, 2017.

ARAÚJO, C. A. A. O que é ciência da informação? Informação e Informação, 
Londrina, v. 19, n. 1, p. 1- 30, jan./abr. 2014.

BARDIN, L. Análise de conteúdo. Lisboa: Edições 70, 2003.

BRASCHER, M.; CAFÉ, L. Organização da informação ou organização do conhecimento. In: ENCONTRO NACIONAL DE PESQUISA EM CIÊNCIA DA INFORMAÇÃO, 9., 2008, São Paulo. Anais... São Paulo: ENANCIB, 2008. p. 1-14.

BUFREM, L. S.; ARBOIT, A. L.; SORRIBAS, T. V. Organização do conhecimento e a teoria do Círculo de Bakhtin. In: PÉREZ PAIS, C.; GONZÁLEZ BONOME, M. de los A. (Ed.). 20 Años del capítulo español de ISKO: actas del X Congreso ISKO capítulo español. Coruña: Universidade da Coruña, 2012. p. 265-281.

CINTRA, A. M. M. et al. Para entender as linguagens documentárias. 2. ed. ão Paulo: Polis, 2002.

CAPURRO, R. Epistemologia e ciência da informação. In: ENCONTRO NACIONAL DE PESQUISA EM CIÊNCIA DA INFORMAÇÃO, 5., 2003, Belo Horizonte. Anais... Belo Horizonte: UFMG, 2003.

CAPURRO, R.; HJØRLAND, B. O conceito de informação. Perspectivas em Ciência da Informação, Belo Horizonte, v. 12, n. 1, p. 148-207, jan./abr. 2007. Tradução do artigo The concept of information publicado no periódico Annual Review of Information Science of Technology no ano de 2003.

ESTEBAN NAVARRO, M. A.; GARCÍA MARCO, F. G. Las “primeras jornadas sobre organización del conocimiento: organización del conocimiento e información científica”. Scire, Saragoça, v. 1, n. 1, p. 149-157, enero/jun. 1995.

HJØRLAND, B. What is Knowledge Organization (KO)? Knowledge organization, Copenhagen, v. 35, n. 2, p. 86-101, July 2008.

LOPES YEPES, José. Teoria da Ciência da Documentação. 2016. Anotações de aula.

MCGARRY, K. O contexto dinâmico da informação. Brasília: Briquet de Lemos, 1999.

MOREIRA, W. et al. Vocabulário controlado para a representação documentária em arquivos correntes da UNESP. In: SEMINÁRIO CIENTÍFICO ARQUIVOLOGIA E BIBLIOTECONOMIA, 4., 2015, Marília. Anais.... Marília: UNESP, 2015. p. não consta.

NATIONAL ARCHIVES OF AUSTRALIA. Developing a functions thesaurus: guidelines for commonwealth agencies. Canberra: NAA, 2003. 
RENDÓN ROJAS, M. A. Relación entre los conceptos: información, conocimiento valor: semejanzas y diferencias. Ciência da Informação, Brasília, v. 34, n. 2, p.52-61, maio/ago. 2005.

SILVA, M. A.; RIBEIRO, F. Das "ciências" documentais à ciência da informação: ensaio epistemológico para um novo modelo curricular. Porto: Afrontamento, 2002.

SILVA, A. M. et al. Arquivística: teoria e prática de uma Ciência da Informação. Porto: Afrontamento, 1999.

SMIT, J. W.; KOBASHI, N. Y. Como elaborar vocabulário controlado para aplicação em arquivos. São Paulo: Arquivo do Estado, 2003

TOGNOLI, N. B. A representação na Arquivística contemporânea. Revista Ibero-Americana de Ciência da Informação, Brasília, v. 5, n. 2, p. 79-92, jul./dez. 2012.

TOGNOLI, N. T.; BARROS, T. H. B. Os processos de representação do conhecimento arquivístico: elementos históricos e conceituais da classificação e descrição. In: GUIMARÃES, J. A. C.; DODEBEI, V. (Org.). Estudos

Avançados em Organização do Conhecimento: organização do conhecimento e diversidade cultural. Marília: Fundepe, 2015, p. 94-99. v. 3.

\title{
Organization and representation of the archival knowledge: in pursuit of a method to construct a functional thesaurus
}

\begin{abstract}
The production and use of archival knowledge in the Information and Communications Technology (ICT) scenario presents a complex environment. Thus, reflecting on the ways of representing the archival knowledge with terminological instruments contributes to informational access. In this perspective, the functional thesauri, as a field of study within the area, act as a complementary solution tool to the problems of access to archival information. Therefore, the present work aims to carry out a methodological systematization of the construction of a functional thesaurus. About the methodological procedures, they are characterized as a bibliographic and exploratory research with a qualitative approach. The Bardin content analysis method was used, which after the pre-analysis and the exploitation of the material (technicalscientific literature), the following categories were grouped: conceptual pragmatic nature, necessary preliminary aspects, functions that the thesaurus performs, in addition to the theoretical aspects evidenced, steps and fundamental actions for the construction of the functional thesaurus. It has been found that, for the construction of functional thesauri, the Australian National Archives manual, pioneer in a functional thesaurus manual, it describes steps and actions
\end{abstract}


necessary for its construction. It is concluded that this trajectory of the construction of a functional thesaurus is going through an initial stage, revealing the need for a theoretical deepening of this subject with other areas of knowledge.

Keywords: Organization of archival knowledge. Functional Thesaurus. Archival Controlled Vocabulary.

Recebido: $16 / 02 / 2018$

Aceito: $19 / 06 / 2018$

${ }^{1}$ Este trabalho é parte da dissertação Organização e representação do conhecimento arquivístico: abordagens para construção de tesauros funcionais (ALENCAR, 2017), defendida pelo Programa de Pós-Graduação em Ciência da Informação da Universidade Estadual de Londrina (UEL).

${ }^{2} \mathrm{O}$ Arquivo Nacional da Austrália é pioneiro em se tratando especificamente de tesauro funcional.

3 SHANNON, Claude; WEAVER, Warren. The mathematical theory of communication. Urbana: University of Illinois Press, 1949. Apud Capurro (2003).

4 FOGL, J. Relations of the concepts 'information' and 'knowledge'. International Forum on Information and Documentation, The Hague, v. 4, n. 1, p. 21-24, 1979. Apud Brascher e Café (2008).

5 FOGL, J. Relations of the concepts 'information' and 'knowledge'. International Forum on Information and Documentation, The Hague, v. 4, n. 1, p. 21-24, 1979. Apud Brascher e Café (2008).

${ }^{6}$ Para McGarry (1999, p. 13), "O aspecto fundamental a respeito de símbolos é que são representações, culturais construídas e aceitas, de coisas, ideias e aspirações. Seus significados dependem inteiramente do grupo social que os utiliza.". 